Article

\title{
Electrochemical Sensor for Explosives Precursors' Detection in Water
}

\author{
Cloé Desmet ${ }^{1}$, Agnes Degiuli ${ }^{1}$, Carlotta Ferrari ${ }^{2}$, Francesco Saverio Romolo ${ }^{3}$, Loïc Blum ${ }^{1}$ \\ and Christophe Marquette ${ }^{1, *}$ \\ 1 Equipe Génie Enzymatique, Membranes Biomimétiques et Assemblages Supramoléculaires, Univ Lyon, \\ Université Lyon1, 43 Bd du 11 Novembre 1918, 69622 Villeurbanne, France; cloe.desmet@outlook.com (C.D.); \\ agnes.degiuli@univ-lyon1.fr (A.D.); loic.blum@univ-lyon1.fr (L.B.) \\ 2 Institut de Police Scientifique (IPS), Université de Lausanne, Dorigny, 1004 Lausanne, Switzerland; \\ carlotta.ferrari23@libero.it \\ 3 Legal Medicine Section-SAIMLAL Department, SAPIENZA University of Rome, Viale Regina Elena, 336, \\ 00161 Roma, Italy; francescosaverio.romolo@uniroma1.it \\ * Correspondence: christophe.marquette@univ-lyon1.fr \\ Academic Editor: Palmiro Poltronieri \\ Received: 9 February 2017; Accepted: 17 March 2017; Published: 22 March 2017
}

\begin{abstract}
Although all countries are intensifying their efforts against terrorism and increasing their mutual cooperation, terrorist bombing is still one of the greatest threats to society. The discovery of hidden bomb factories is of primary importance in the prevention of terrorism activities. Criminals preparing improvised explosives (IE) use chemical substances called precursors. These compounds are released in the air and in the waste water during IE production. Tracking sources of precursors by analyzing air or wastewater can then be an important clue for bomb factories' localization. We are reporting here a new multiplex electrochemical sensor dedicated to the on-site simultaneous detection of three explosive precursors, potentially used for improvised explosive device preparation (hereafter referenced as B01, B08, and B15, for security disclosure reasons and to avoid being detrimental to the security of the counter-explosive EU action). The electrochemical sensors were designed to be disposable and to combine ease of use and portability in a screen-printed eight-electrochemical cell array format. The working electrodes were modified with different electrodeposited metals: gold, palladium, and platinum. These different coatings giving selectivity to the multi-sensor through a "fingerprint"-like signal subsequently analyzed using partial least squares-discriminant analysis (PLS-DA). Results are given regarding the detection of the three compounds in a real environment and in the presence of potentially interfering species.
\end{abstract}

Keywords: bomb factory; electrochemical array; explosive precursors; improvised explosives; partial least squares-discriminant analysis

\section{Introduction}

Although all countries are intensifying their efforts against terrorism and increasing their mutual cooperation, terrorist bombing is still one of the greatest threats to society. The discovery of hidden bomb factories is of primary importance in the prevention of terrorism activities. Different explosives have been widely used in improvised explosive devices (IEDs) by terrorists, due to their relatively simple preparation protocol. For instance, triacetone triperoxide (TATP), cyclotrimethylenetrinitramine (RDX), hexamethylene triperoxide diamine (HMTD), and trinitrotoluene (TNT) can be synthesized using commercially available chemicals following recipes that can be found on the Internet. Commercially available chemicals used to prepare improvised explosives (IE) are called "precursors" and are regulated in Europe by the European Parliament and Council Regulation (EU) No. 98/2013 on the marketing and 
use of explosives precursors, adopted on 15 January 2014 [1]. Consequently, growing security concerns have generated urgent needs for innovative tools for on-field screening of precursors for IE manufacturing. In numerous security applications and scenarios, the reliable multi-parametric detection of these precursors using a small portable and disposable sensor may be a real asset.

During the last few years, an important increase of research within this area has been observed, through development of new detection approaches and improvements of existing techniques. Spectroscopic approaches have been the most widely explored [2-7], but quartz crystal microbalance (QCM), ion chromatography [8], capillary electrophoresis [9], surface-enhanced Raman scattering (SERS) [10], nanotechnology based-methods (using molecularly imprinted polymers [11], nanotubes, or nanoparticles), and sensor techniques [12-16] have also been largely described. Amongst the different types of sensors developed to address this need, the electrochemical sensors [17-19] present the advantages of being fast, inexpensive, and adapted to miniaturization. Nevertheless, the existing electrochemical devices rarely enabled a label-free multi-parametric detection. We are reporting here a new multiplex electrochemical sensor dedicated to the on-site simultaneous detection of three explosive precursors (hereafter referenced as B01, B08, and B15 for security disclosure reasons and to avoid being detrimental to the security of the counter-explosive EU action), potentially used for improvised explosive devices' preparation. The electrochemical chips were designed to be disposable and to combine ease of use and portability thanks to a simple and inexpensive screen-printing fabrication technique. An eight-electrode array was then produced, composed of four different electrode compositions (gold, platinum, palladium, and carbon). This electrode composition was of high significance since this is the basis of the electrochemical signature of the different compounds. This electrochemical signature was subsequently analyzed using partial least squares-discriminant analysis (PLS-DA) in order to classify and discriminate the different explosive precursors.

\section{Materials and Methods}

\subsection{Materials}

Ammonium chloride $\left(\mathrm{NH}_{4} \mathrm{Cl}\right)$, calcium chloride $\left(\mathrm{CaCl}_{2}\right)$, chloroplatinic acid hexahydrate $\left(\mathrm{H}_{2} \mathrm{PtCl}_{6}\right)$, gold (III) chloride $\left(\mathrm{HAuCl}_{4}\right)$, palladium acetate $\left(\mathrm{Pd}(\mathrm{OAc})_{2}\right)$, hexamethylenetetramine (hexamine), and whey from bovine milk were purchased from Sigma (Lyon, France). Magnesium chloride $\left(\mathrm{MgCl}_{2}\right)$, sodium acetate, sodium chloride $(\mathrm{NaCl})$, sodium dihydrogenophosphate $\left(\mathrm{Na}_{2} \mathrm{HPO}_{4}\right)$, and hydrochloric acid $(\mathrm{HCl})$ were obtained from Prolabo (Fontenay-sous-Bois, France). Bacteriological peptone was purchased from Fluka (Saint-Quentin, Fallavier, France).

All solutions were prepared with ultrapure water $(18.2 \mathrm{M} \Omega)$.

\subsection{Methods}

\subsubsection{Working Electrode Modification}

The electrode array (DRP-8x110-U20) and the connector (CAST8X) were purchased from Dropsens (Llanera, Spain). Each of the eight electrodes is composed of a carbon paste working electrode, a carbon paste counter electrode, and a silver/silver chloride reference electrode.

Six of the eight working electrodes were modified in order to generate different surfaces for electrochemical measurement (Figure 1). Three metals were independently electrodeposited on two working electrodes through galvanostatic chronopotentiometry as previously described [20]. A constant current was applied for $10 \mathrm{~min}$, leading to a fixed charge, optimized for each metal solution. In practice, a drop of $40 \mu \mathrm{L}$ of the solution was deposited on the active area prior to chronopotentiometry. The gold deposition was carried out using a fixed current of $-300 \mu \mathrm{A}$, in the presence of a solution of $10 \mathrm{mM} \mathrm{HAuCl} 4$ in $0.1 \mathrm{M} \mathrm{HCl}$. A fixed current of $-150 \mu \mathrm{A}$ was applied for the palladium and platinum deposition in the presence of a solution composed of $10 \mathrm{mM}$ or $\mathrm{Pd}(\mathrm{OAc})_{2}$ or $\mathrm{H}_{2} \mathrm{PtCl}_{6}$ in $0.1 \mathrm{M} \mathrm{HCl}$. Finally, a fixed current of $-150 \mu \mathrm{A}$ was applied to a bare carbon working 
electrode in a solution of $0.1 \mathrm{M} \mathrm{HCl}$. Following each deposition, the electrode chips were rinsed with ultrapure water.

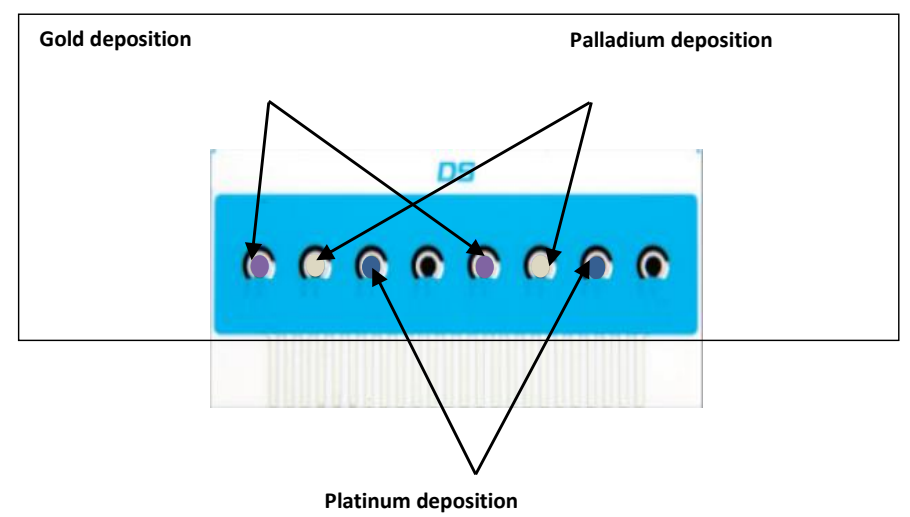

Figure 1. The eight-electrode chip with its metal deposition, which will lead to the acquisition of an electrochemical signature.

\subsubsection{Electrochemical Measurements}

Sensing of the three precursors has been achieved through their electrochemical oxido-reduction using four different electrodes. The obtained cyclic voltammograms were then merged to build specific signatures.

Cyclic voltammetry measurements were achieved simultaneously on the eight electrodes using a multichannel potentiostat ( $\mu 8000$ from Dropsens, Llanera, Spain) at a $300 \mathrm{mV} \cdot \mathrm{s}^{-1}$ scan rate. The potential range used was +1.0 to $-1.0 \mathrm{~V}$ for the gold-modified working electrodes and -1.0 to $+0.5 \mathrm{~V}$ for the palladium-, platinum-, and non-modified carbon working electrodes. In order to evaluate the matrix effect, measurements were performed in different aqueous solution: (i) $\mathrm{NaCl} 0.1 \mathrm{M}$ electrolyte solution in milliQ water; (ii) tap drinking water; (iii) tap non-drinkable water; (iv) soap water (GEH dish washing soap $0.1 \% \mathrm{v} / \mathrm{v}$ in tap drinking water); and (iv) artificial sewage water composed of tap drinking water added of whey $500 \mathrm{mg} / \mathrm{L}$, peptone $100 \mathrm{mg} / \mathrm{L}, \mathrm{Na}_{2} \mathrm{HPO}_{4} 54 \mathrm{mg} / \mathrm{L}$, $\mathrm{NH}_{4} \mathrm{Cl} 178.3 \mathrm{mg} / \mathrm{L}$, sodium acetate $41.7 \mathrm{mg} / \mathrm{L}, \mathrm{NaCl} 58.4 \mathrm{mg} / \mathrm{L}, \mathrm{CaCl}_{2} \cdot 2 \mathrm{H}_{2} \mathrm{O} 14.7 \mathrm{mg} / \mathrm{L}, \mathrm{MgCl}_{2} \cdot 6 \mathrm{H}_{2} \mathrm{O}$ $20.3 \mathrm{mg} / \mathrm{L}$, and $\mathrm{KCl} 7.4 \mathrm{mg} / \mathrm{L}$.

\subsubsection{Electrochemical Data Analysis}

Partial least squares-discriminant analysis (PLS-DA) [21] was used as the pattern recognition technique for the computation of the classification models applied to determine the predicted probability of the presence of the three targets. The performance of each classification model was evaluated on the basis of the following parameters:

- Sensitivity (SENS): the percentage of objects of each modelled class correctly accepted by the class model.

- Specificity (SPEC): the percentage of objects of the other classes correctly rejected by the class model.

- Efficiency (EFF): the geometric mean of sensitivity and specificity.

Once the optimal model for each target substance selected, the probability of the presence of the different target substances for any new measurement was computed. All data analysis were performed using the PLS Toolbox ver. 7.5 and ver. 7.8.2 (Eigenvector Research Inc., Wenatchee, WA, USA) and all routines were written in MATLABC platform 7.11 R2010b (The Mathworks Inc., Novi, MI, USA). 


\subsubsection{Operational Setup}

Real condition measurements were carried out with the following operational setup composed of:

- A multichannel potentiostat (Figure 2A) connected through GSM (Global System for Mobile Communication) to the central control system (using TEKEVER communication tool box [22]).

- A wetting system fitting the sewage system and in which the eight-electrode array is inserted (Figure 2B). This setup enabled the electrode array to be immersed in flushing water.
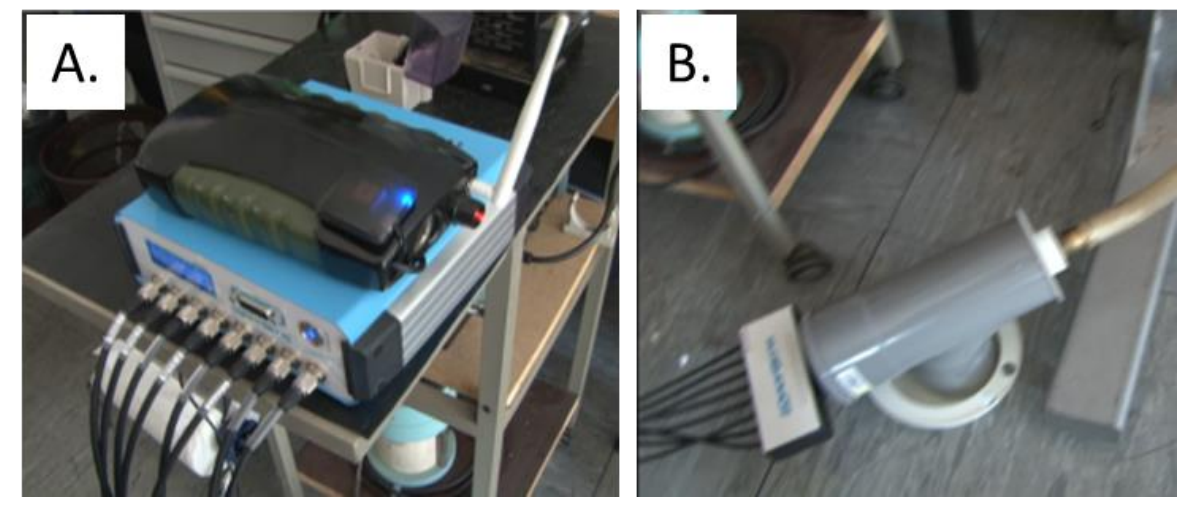

Figure 2. Views of the operational electrochemical setup composed by the multichannel potentiostat (A) and a wetting system (B).

\section{Results and Discussion}

Electrochemical sensors combined with cyclic voltammetry methods generate a specific signal from oxidation and reduction of particular molecules. This signal may also vary with the electrode composition but the differentiation between two chemicals is hardly possible using only one voltammogram. To solve this issue, a signature of several voltammograms obtained on different surfaces, used like a compound "fingerprint", may drastically increase the result's specificity. In the present study, an electrochemical chip has been developed with the objective of being able to discriminate between different chemicals.

\subsection{Electrodeposition}

Modifying the electrode network in an addressed manner was a key step in the present study to generate different measurement surfaces useful for signature determination. Three metals, gold, platinum, and palladium, were chosen for this purpose according to their well-known electrochemical properties and stability as working electrodes [23]. The electrodeposition of each metal was then controlled and optimized in order to obtain a homogenous coverage of the working electrodes (Figure 3A-D.). Each deposition process was validated through the analysis of the $I=f(t)$ curves, but also thanks to scanning electronic microscopy observations.

A more complete characterization of the modified surfaces was also realized using scanning electron microscopy observation coupled with energy dispersive X-ray spectroscopy analysis (Figure 3I-L). The surface roughness was found to be really high, leading to potentially high active areas, a good point when looking at electrochemical signal optimization. Indeed, the higher the specific area, the higher the current per surface unit recorded for one compound. The surfaces' observations also demonstrated the presence of metallic particles' multilayers on the working electrode area. The elemental analysis enabled the validation of the full coverage of the surface by the particles, with an extremely low carbon signal coming from the underlying electrode, proof of the total coverage of the surface during the electrodeposition process. That point was also a good characteristic since each electrode will then have a specific signal, only coming from the particular deposited metal, without any mixed multi-material electrochemical signal. 

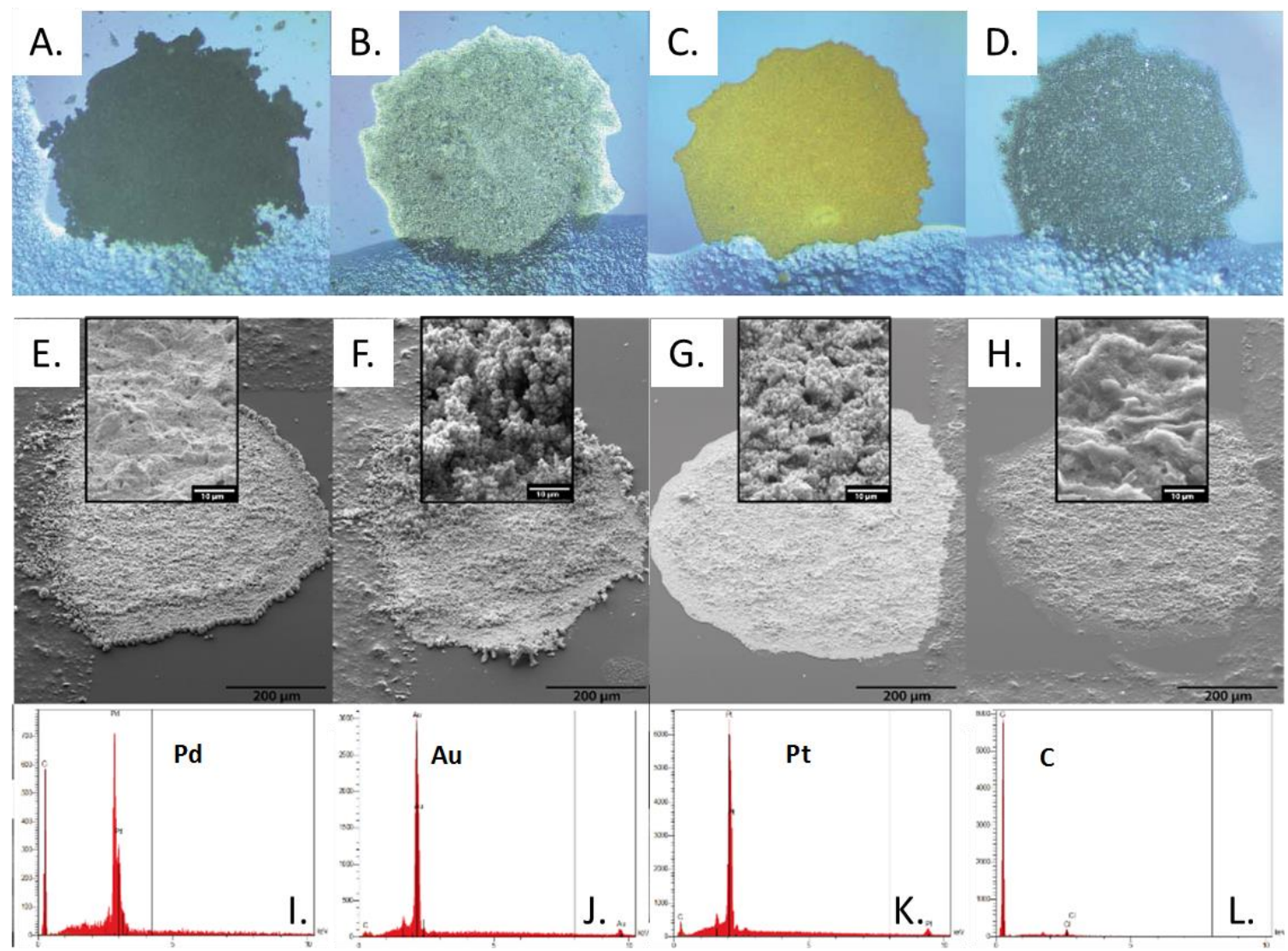

Figure 3. Optical microscopy images of (A) palladium; (B) platinum; (C) gold; and (D) bare carbon electrodes. SEM observation of the surface of $(\mathrm{E})$ palladium; $(\mathbf{F})$ platinum; $(\mathrm{G})$ gold; and $(\mathbf{H})$ bare carbon electrodes. Bottom: EDX analysis of the surfaces (I-L).

\subsection{Signature Definition and Data Analysis}

Using the individual signals of the different electrodes for each compound, an approach based on the creation of a unique signature for each target was applied so as to take full advantage of the information provided by the different electrodes on the same sample. To this aim, the signals acquired with the four electrode surfaces were merged together as a unique new signal after a block of data was scaled to unit variance. This approach led to a signature with equal importance of the information provided by the different electrodes. A schematic representation of this approach is shown in Figure 4 .

These signatures were acquired to generate an experimental database of target compounds in multiple aqueous environments, such as distilled water, drinking water, non-drinking water, soapy water, and artificial waste water. This approach was used to build a stronger database than just a database produced in pure water and to insert in the model the expected variations related to potential matrix effects.

In addition to the three main target substances (B01, B08, and B15), data were also acquired on additional target substances B04, B05, and B11, and on the interfering species Int09, representative of common cleaning products (once again kept as confidential).

The composition of the dataset used for the calculation of the PLS-DA classification models of target B01, B08, and B15 is reported in Table 1. 

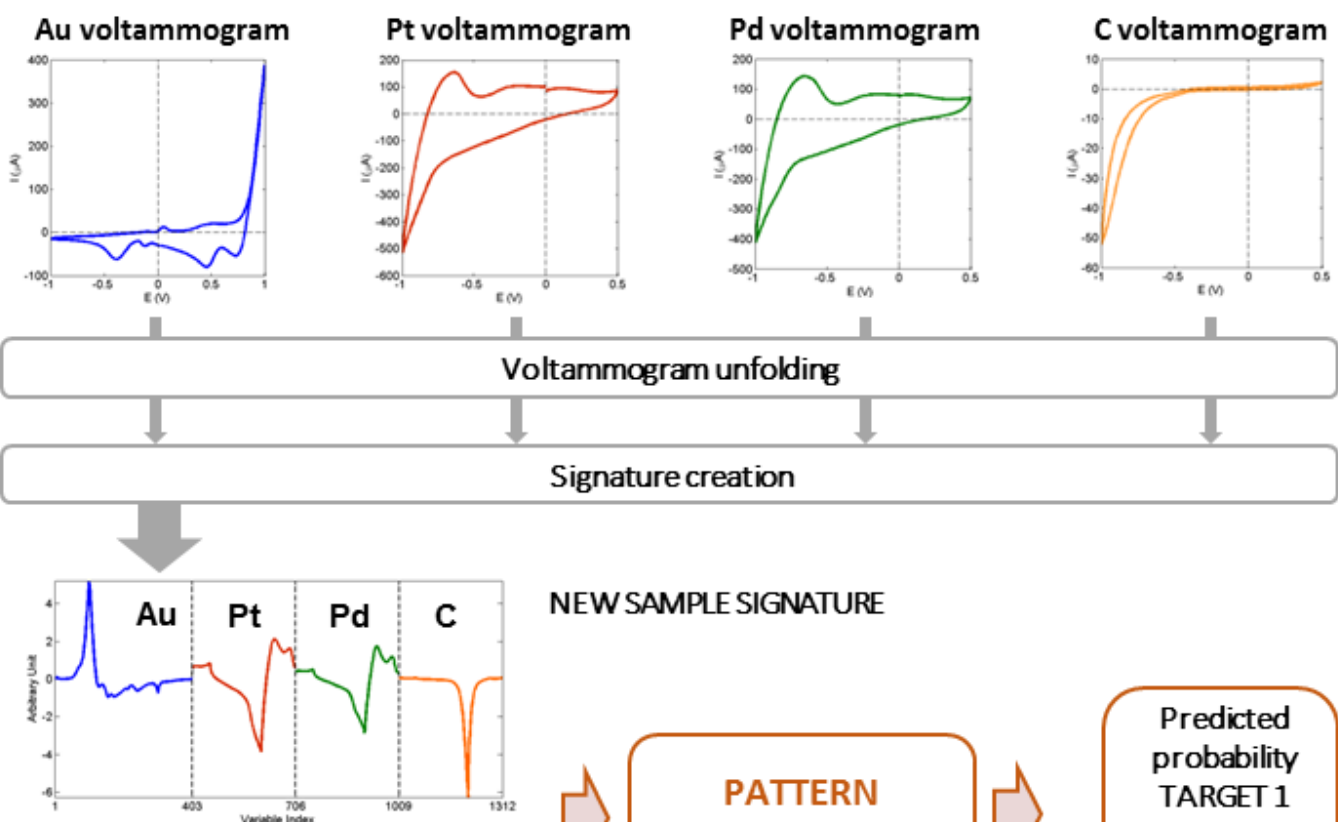

NEW SAMPLE SIGNATURE
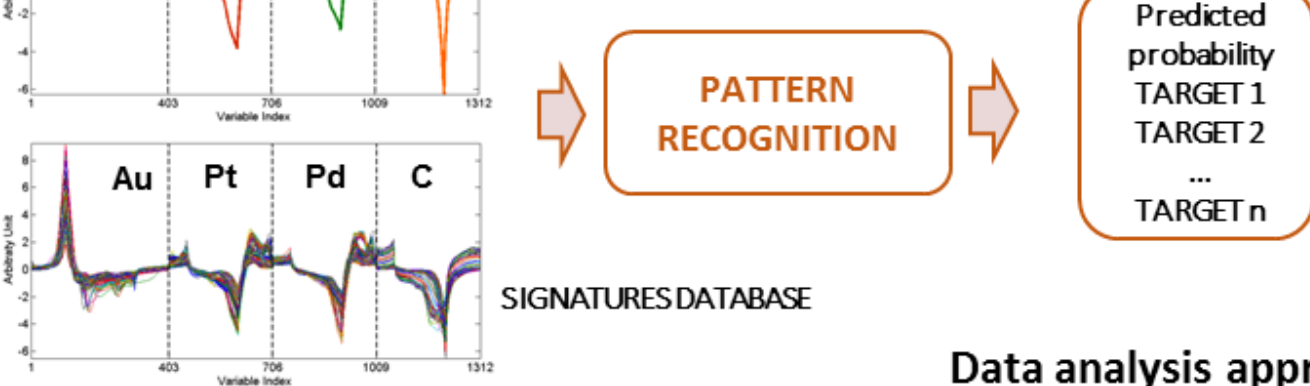

SIGNATURESDATABASE

Data analysis approach.

Figure 4. Electrochemical data analysis approach. From each set of four voltammograms obtained from the four different electrodes, voltammograms were unfolded, auto-scaled, and merged to generate a unique signature.

Table 1. Composition of the training and test sets used to compute and validate the classification models of the EC sensor.

\begin{tabular}{|c|c|c|c|c|}
\hline Target & Class & $\begin{array}{l}\text { Number of Spectra } \\
\text { for Training }\end{array}$ & $\begin{array}{c}\text { Number of Spectra } \\
\text { for Test }\end{array}$ & $\begin{array}{c}\text { Total Number } \\
\text { of Spectra }\end{array}$ \\
\hline \multirow{2}{*}{ B01 } & Target & 25 & 11 & 36 \\
\hline & No Target & 187 & 122 & 309 \\
\hline \multirow{2}{*}{ B08 } & Target & 33 & 22 & 55 \\
\hline & No Target & 179 & 111 & 290 \\
\hline \multirow{2}{*}{ B15 } & Target & 33 & 21 & 54 \\
\hline & No Target & 179 & 112 & 291 \\
\hline
\end{tabular}

For explanatory purpose, the signatures obtained during the training step for each of the three target compounds are presented in Figure 5. Here, for the sake of clarity, are presented only the experiments performed in water, soapy water, and artificial waste water. The peak positions and intensity of each target using each electrode are given in Supplementary Materials Table S1. 


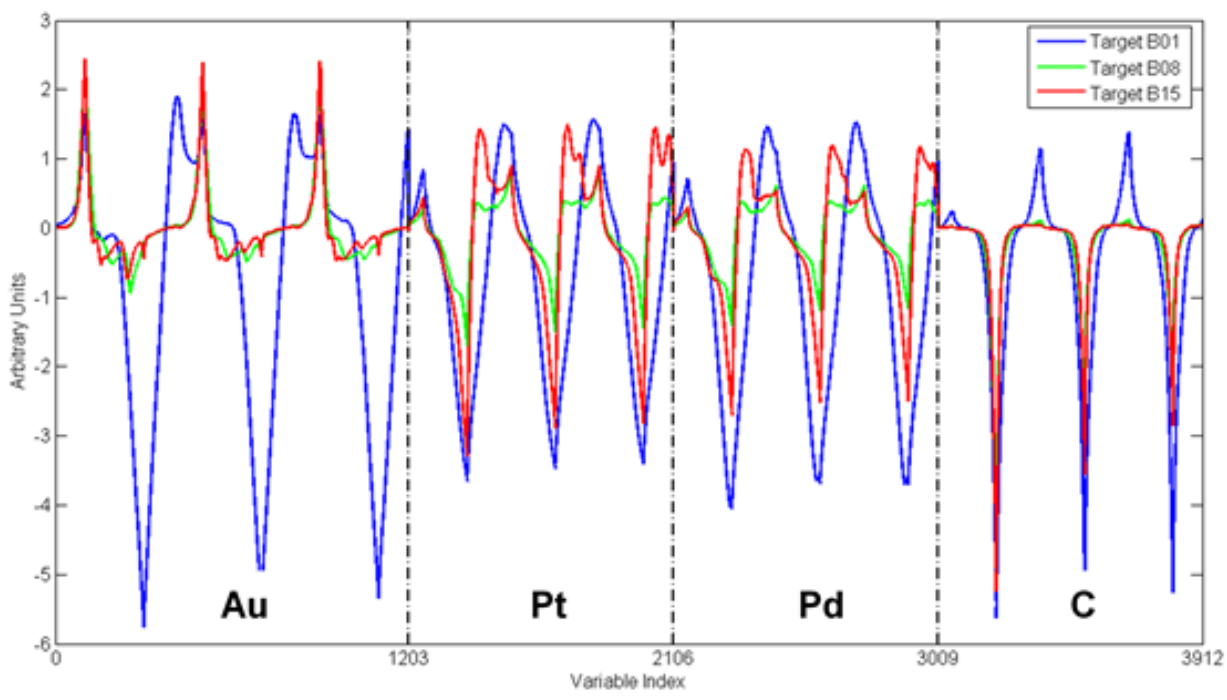

Figure 5. Signatures obtained during the training step for the three target compounds. Measurements presented here were performed in water, soapy water, and artificial waste water.

\subsection{Explosive Precursors' Detection Using Pattern Recognition}

The above mentioned database was then used to compute PLS-DA classification models for the three target compounds. In this context, we performed a more comprehensive evaluation of the effect of several spectra pre-treatment methods in removing the uninformative variation while retaining the most informative one, so as to optimize model performance. To this aim, several PLS-DA models have been calculated for each target, considering the different spectra pre-processing methods listed in Table 2.

Table 2. The evaluated data pre-treatment.

\begin{tabular}{cc}
\hline PLS-DA Cycle & Spectra Pre-Treatment Method \\
\hline 1 & None \\
2 & Mean centre (MC) \\
3 & Auto-scale (Auto) \\
4 & Standard normal variate (SNV) \\
5 & Standard normal variate (SNV) + MC \\
6 & Standard normal variate (SNV) + Auto \\
\hline
\end{tabular}

The results obtained from this pre-treatment optimization step (data not shown for brevity) have indicated that the highest efficiency values in cross-validation and in prediction were achieved by applying pre-treatment 6: standard normal variate (SNV) followed by auto-scale. The statistical results of the final models are reported in Table 3.

Table 3. Results of the classification models calculated on the final electrochemical database (i.e., pre-treatment 6).

\begin{tabular}{cccc}
\hline \multirow{2}{*}{ Target } & \multicolumn{3}{c}{ Efficiency (\%) } \\
\cline { 2 - 4 } & Cal. (Calibration) & CV (Cross-Validation) & Pred. (Prediction) \\
\hline B01 & 100.00 & 100.00 & 95.34 \\
B08 & 100.00 & 92.15 & 99.55 \\
B15 & 100.00 & 97.65 & 100.00 \\
\hline
\end{tabular}

The final classification model performance in discriminating one particular target with respect to signals of the other targets and interfering species is shown in Figure 6. In particular, the predicted values obtained by applying the classification models for targets B01, B08, and B15 are reported in 
Figure $6 \mathrm{~A}-\mathrm{C}$, respectively. As can be seen, each of the targets was clearly classified above its predicting threshold and with minimum false negative or positive errors. Indeed, only one false negative and one false positive were observed for B01, while none were observed for the two other targets. Moreover, different target preparations were also tested for B08 and B15, which led to correct classification of the compounds. The classification model and data pre-treatment was then proved to be efficient and robust enough to be tested in realistic conditions using the wetting setup described in Figure 2.

A.

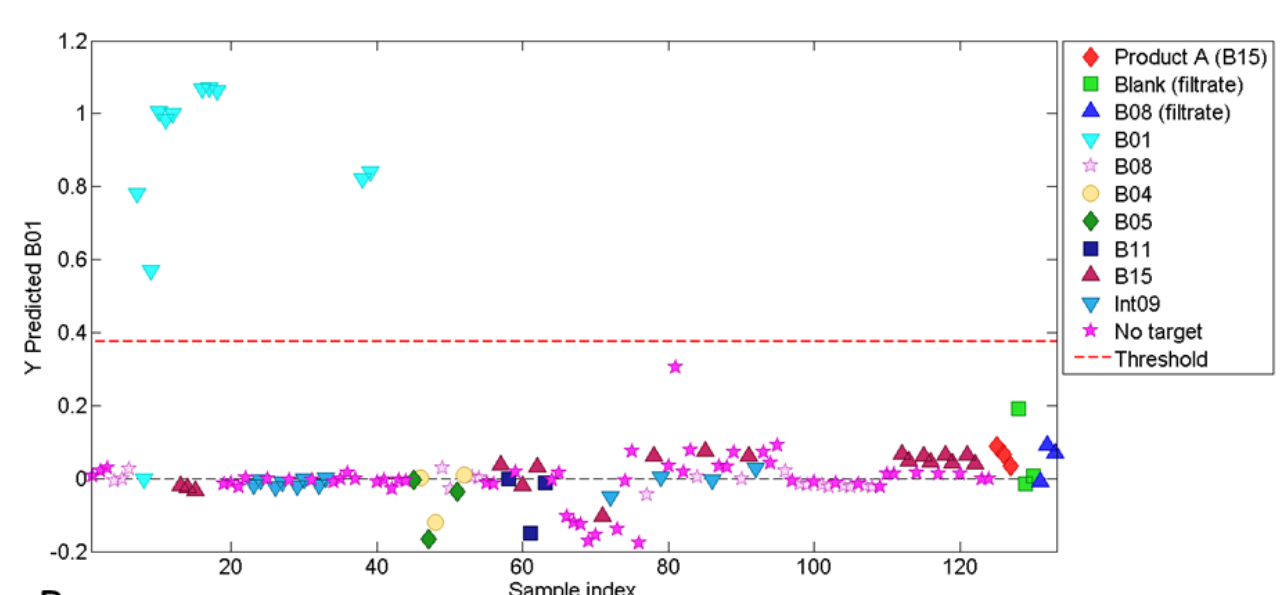

B.

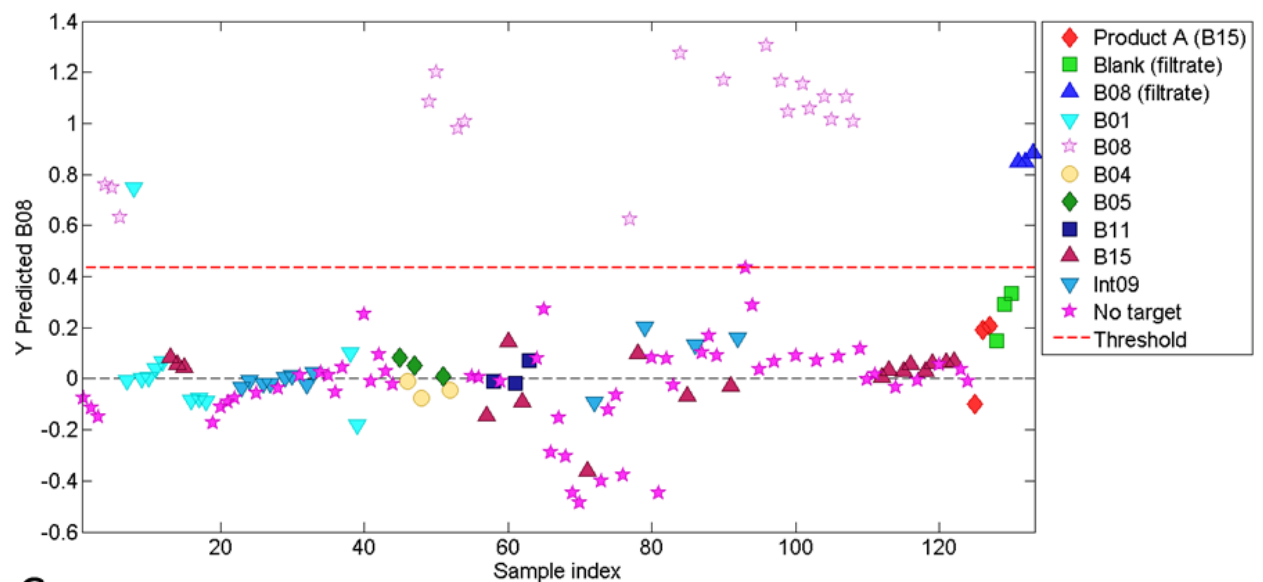

C.

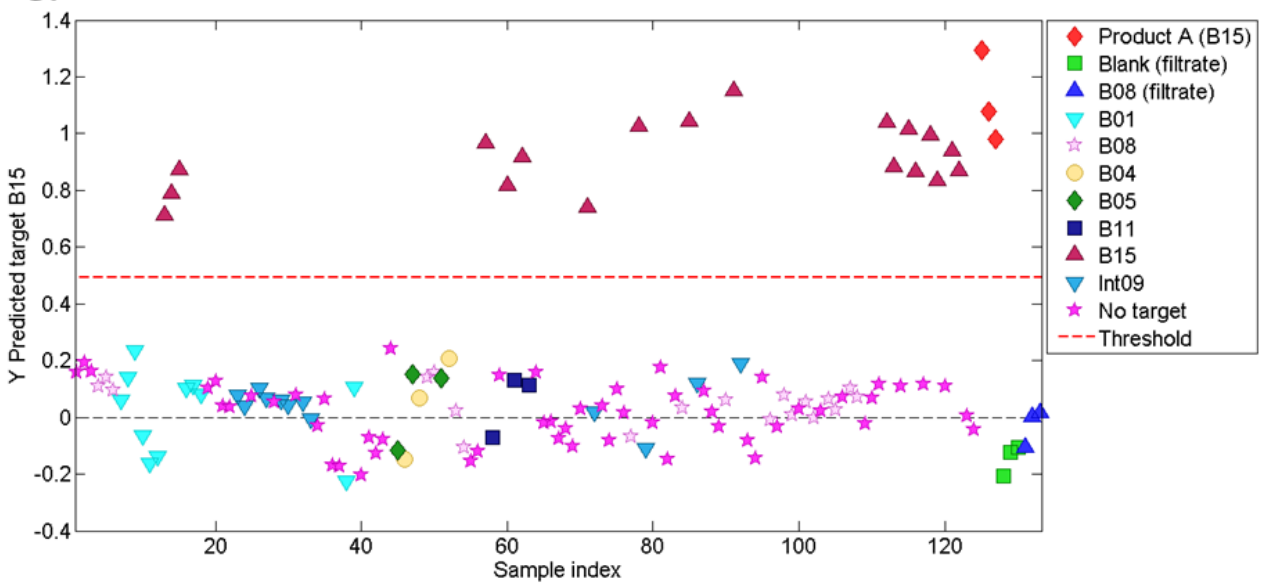

Figure 6. Predicted values obtained by applying on the test set the classification model for target B01 (A); target B08 (B); and target B15 (C). 


\subsection{Realistic Conditions Testing}

The final assessment of the capability of the electrochemical sensor to detect improvised explosive precursors directly in sewage drain water from a simulated bomb factory has been performed using the experimental setup described in Figure 2. For this setup, the electrochemical measurement is triggered by the wetting of the electrode array following a flushing of waste water from a sink in which a vessel used for IE preparation has been washed using local tap water. Here, concentrations up to $100 \mathrm{mM}$ of each of the compounds are usually found in water discharge. These experiments were performed during improvised explosive preparation campaigns within the Italian Air Force base in Pratica di Mare (Italy) and the Swedish Defense Research Agency (FOI) facility in Grindsjön (Sweden).

The results obtained are presented in Table 4. The results are given in terms of predicted probability of the presence of each compound, but also in terms of a properly raised alarm (color code). As can be seen, the majority of the tested scenarios was giving correct prediction of the waste water content and enabled the raising of a proper alarm. Only three tests gave false positive results for B08 in the presence of B01, leading to a rising of the alarm for a wrong set on compounds, i.e., B01 + B08 instead of only B01.

Table 4. Results obtained using realistic testing conditions. The green box indicates a correct classification for alarm triggering of the system. A red box indicates a false positive alarm. An orange box indicates an unclear classification resulting in a low confidence alarm.

\begin{tabular}{|c|c|c|c|c|}
\hline \multirow{2}{*}{ Test Number } & \multirow{2}{*}{ Target } & \multicolumn{3}{|c|}{ Predicted Probability (\%) } \\
\hline & & B01 & B08 & B15 \\
\hline \multirow[b]{2}{*}{1} & B15 & 0.00 & 0.00 & 100.00 \\
\hline & B01 & 100.00 & 0.00 & 0.00 \\
\hline 2 & B08 & 0.00 & 93.84 & 0.00 \\
\hline 3 & B01 & 100.00 & 100.00 & 0.00 \\
\hline 4 & B15 & 0.00 & 0.00 & 100.00 \\
\hline 5 & B01 & 100.00 & 92.44 & 0.00 \\
\hline 6 & B15 & 0.00 & 0.00 & 100.00 \\
\hline 7 & Blank & 0.00 & 0.31 & 0.00 \\
\hline 8 & Blank & 0.00 & 0.31 & 0.00 \\
\hline 9 & B15 & 0.00 & 0.00 & 100.00 \\
\hline 10 & B08 & 28.35 & 99.88 & 0.00 \\
\hline 11 & Blank & 0.00 & 0.16 & 0.00 \\
\hline 12 & B15 & 0.00 & 0.00 & 100.00 \\
\hline 13 & B01 & 100.00 & 100.00 & 0.00 \\
\hline 14 & Blank & 0.00 & 0.66 & 0.82 \\
\hline 15 & B08 & 0.00 & 99.66 & 0.00 \\
\hline 16 & Blank & 0.00 & 0.67 & 0.00 \\
\hline 17 & B08 & 0.00 & 93.10 & 0.00 \\
\hline 18 & B08 & 0.00 & 93.84 & 0.00 \\
\hline 19 & Blank & 0.00 & 0.31 & 0.00 \\
\hline
\end{tabular}

\section{Conclusions}

The developed electrochemical sensor showed a number of key features, including portability, battery stand-alone operability, wireless operability, and possibility to be easily hidden in the sewage system.

At the analytical level, it was successfully trained in the laboratory (data pre-treatment optimization, model prediction training) and tested under relevant environmental conditions, i.e., in the presence of interfering species and other potential targets. Its capability to detect the three target compounds in waste water obtained during improvised explosive preparation has also been demonstrated. It is finally worth mentioning that the electrochemical sensor was also successfully tested, integrated in a network of sensors with an "expert system" providing not only detection at the sensor level, but also data fusion of chemical information provided by the different sensors deployed. 
Supplementary Materials: The following are available online at www.mdpi.com/2078-1547/8/1/10/s1, Table S1: Position (potential) and amplitude (current) of the observed peaks for each target on each electrode.

Acknowledgments: This work has been supported by the European Commission Program STREP-FP7-SEC2010-1-Bomb Factory Detection by Networks of Advanced Sensors grant agreement No. 261685. The authors would like to thank Luigi Cassioli and Silvana Grossi of the Italian Air Force for their support during the tests at the Pratica di Mare (Italy) base and Pedro Santo Antonio from TEKEVER, Obidos (Portugal), for developing the software connecting the sensors of the BONAS network. The authors would also like to thank FOI (Swedish Defence Research Agency) head of research and leading Swedish explosive expert Henrik Östmark.

Author Contributions: Cloé Desmet, Agnes Degiuli, Carlotta Ferrari, and Christophe Marquette conceived and designed the experiments; Cloé Desmet, Agnes Degiuli, and Carlotta Ferrari performed the experiments; Carlotta Ferrari, Loic Blum, and Christophe Marquette analyzed the data; Carlotta Ferrari, Francesco Saverio Romolo, Cloé Desmet and Christophe Marquette wrote the paper.

Conflicts of Interest: The authors declare no conflict of interest.

\section{References}

1. Regulation (EU) No 98/2013 of the European Parliament and of the Council of 15 January 2013 on the Marketing and Use of Explosives Precursors Text with EEA Relevance. Available online: http:/ / eur-lex.europa.eu/legalcontent/EN/TXT/?uri=uriserv:OJ.L_.2013.039.01.0001.01.ENG (accessed on 11 Octorber 2013).

2. King, J.D.; de los Santos, A. Development and evaluation of magnetic resonance technologies, particularly NMR, for detection of explosives. Appl. Magn. Reson. 2004, 25, 535-565. [CrossRef]

3. Barras, J.; Gaskell, M.J.; Hunt, N.; Jenkinson, R.I.; Mann, K.R.; Pedder, D.A.G.; Shilstone, G.N.; Smith, J.A.S. Detection of ammonium nitrate inside vehicles by nuclear quadrupole resonance. Appl. Magn. Reson. 2004, 25, 411-437. [CrossRef]

4. Moros, J.; Lorenzo, J.A.; Lucena, P.; Tobaria, L.M.; Laserna, J.J. Simultaneous raman spectroscopy-laserinduced breakdown spectroscopy for instant standoff analysis of explosives using a mobile integrated sensor platform. Anal. Chem. 2010, 82, 1389-1400. [CrossRef] [PubMed]

5. Ramírez, M.L.; Félix-Rivera, H.; Sánchez-Cuprill, R.A.; Hernández-Rivera, S.P. Thermal-spectroscopic characterization of acetone peroxide and acetone peroxide mixtures with nitrocompounds. J. Therm. Anal. Calorim. 2010, 102, 549-555. [CrossRef]

6. Cheng, S.; Dou, J.; Wang, W.; Chen, C.; Hua, L.; Zhou, Q.; Hou, K.; Li, J.; Li, H. Dopant-assisted negative photoionization ion mobility spectrometry for sensitive detection of explosives. Anal. Chem. 2012, 85, 319-326. [CrossRef] [PubMed]

7. Östmark, H.; Nordberg, M.; Carlsson, T.E. Stand-off detection of explosives particles by multispectral imaging Raman spectroscopy. Appl. Opt. 2011, 50, 5592-5599. [CrossRef] [PubMed]

8. Johns, C.; Shellie, R.A.; Potter, O.G.; O’Reilly, J.W.; Hutchinson, J.P.; Guijt, R.M.; Breadmore, M.C.; Hilder, E.F.; Dicinoski, G.W.; Haddad, P.R. Identification of homemade inorganic explosives by ion chromatographic analysis of post-blast residues. J. Chromatogr. 2008, 1182, 205-214.

9. Hopper, K.G.; LeClair, H.; McCord, B.R. A novel method for analysis of explosives residue by simultaneous detection of anions and cations via capillary zone electrophoresis. Talanta 2005, 67, 304-312. [CrossRef] [PubMed]

10. Hakonen, A.; Andersson, P.O.; Schmidt, M.S.; Rindzevicius, T.; Käll, M. Explosive and chemical threat detection by surface-enhanced Raman scattering: A review. Anal. Chim. Acta 2015, 893, 1-13. [CrossRef] [PubMed]

11. Apodaca, C.D.; Pernites, R.B.; del Mundo, F.R.; Advincula, R.C. Detection of 2,4-dinitrotoluene (DNT) as a model system for nitroaromatic compounds via molecularly imprinted short-alkyl-chain SAMs. Langmuir 2011, 27, 6768-6779. [CrossRef] [PubMed]

12. Wang, J. Microchip devices for detecting terrorist weapons. Anal. Chim. Acta 2004, 507, 3-10. [CrossRef]

13. Singh, S. Sensors-An effective approach for the detection of explosives. J. Hazard. Mater. 2007, 144, 15-28. [CrossRef] [PubMed]

14. Liu, J.; Li, Y.; Huang, X.; Zhu, Z. Tin oxide nanorod array-based electrochemical hydrogen peroxide biosensor. Nanoscale Res. Lett. 2010, 5, 1177-1181. [CrossRef] [PubMed]

15. Bromberg, A.; Mathies, R.A. Homogeneous immunoassay for detection of TNT and its analogues on a microfabricated capillary electrophoresis chip. Anal. Chem. 2003, 75, 1188-1195. [CrossRef] [PubMed] 
16. Charles, P.T.; Adams, A.A.; Howell, P.B.; Trammell, S.A.; Deschamps, J.R.; Kusterbeck, A.W. Fluorescence-based sensing of 2,4,6-trinitrotoluene (TNT) using a multi-channeled poly(methyl methacrylate) (PMMA) microimmunosensor. Sensors 2010, 10, 876-889. [CrossRef] [PubMed]

17. Wang, J. Electrochemical sensing of explosives. Electroanalysis 2007, 19, 415-423. [CrossRef]

18. Chen, W.; Cai, S.; Ren, Q.; Wen, W.; Zhao, Y. Recent advances in electrochemical sensing for hydrogen peroxide: A review. Analyst 2012, 137, 49-58. [CrossRef] [PubMed]

19. Yang, Q.; Liang, Y.; Zhou, T.; Shi, G.; Jin, L. TNT determination based on its degradation by immobilized HRP with electrochemical sensor. Electrochem. Commun. 2008, 10, 1176-1179. [CrossRef]

20. Corgier, B.P.; Li, F.; Blum, L.J.; A, C. On-chip chemiluminescent signal enhancement using nanostructured gold-modified carbon microarrays. Langmuir 2007, 23, 8619-8623. [CrossRef] [PubMed]

21. Barker, M.; Rayens, W.S. Partial least squares for discrimination. J. Chemom. 2003, 17, 166-173. [CrossRef]

22. Ferrari, C.; Ulrici, A.; Romolo, F. Expert system for bomb factory detection by networks of advance sensors. Challenges 2017, 8, 1. [CrossRef]

23. Chandler, G.K.; Genders, J.D.; Pletcher, D. Electrodes based on noble metals. Platin. Met. Rev. 1997, 41, 54-63.

(c) 2017 by the authors. Licensee MDPI, Basel, Switzerland. This article is an open access article distributed under the terms and conditions of the Creative Commons Attribution (CC BY) license (http:/ / creativecommons.org/licenses/by/4.0/). 